Article

\title{
Populism and Political Knowledge: The United States in Comparative Perspective
}

\author{
Henry Milner \\ Chair in Electoral Studies, Department of Political Science, University of Montreal, Montreal QC, H3S1N4, Canada; \\ E-Mail: henry.milner@umontreal.ca
}

Submitted: 14 October 2019 | Accepted: 6 February 2020 | Published: 5 March 2020

\begin{abstract}
This article addresses the link between political knowledge and populist attitudes in the United States (US) in comparative perspective. At the beginning of the new decade, populism in the US is associated with support for the Republican party and Donald Trump in particular, and that is how I address it here. Using secondary data from a number of related studies, we find that, overall, support for Trump is not only negatively related to political knowledge, but also to other factors that make his supporters unaware of their being misinformed. This is because, more than for others, partisan cues serve them as a basis for their factual beliefs about political actors and events and assessments of the beliefs of others. While political knowledge has long been comparatively low in the US, as I show in the early part of the article, the relationship between misinformation and populism (i.e., support for Trump) is seen as a new and especially worrisome element. In the concluding section I address what, if anything, could be done to address this situation.
\end{abstract}

\section{Keywords}

Donald Trump; political knowledge; political misinformation; populism; tribalism; United States

Issue

This article is part of the issue "Leadership, Populism, and Power" edited by Cristine de Clercy (Western University, Canada).

(C) 2020 by the author; licensee Cogitatio (Lisbon, Portugal). This article is licensed under a Creative Commons Attribution 4.0 International License (CC BY).

\section{Introduction}

In addressing the relationship between low political knowledge and the emergence of populist attitudes, I begin by comparing the political knowledge of Americans to that of people in comparable countries, bringing to bear data based on responses to political knowledge questions in cross-national surveys. By first breaking the results down by generation, I find a trend whereby political knowledge is becoming more dependent on education, and that this is especially true of the United States (US). The resulting challenge is that of civic literacy: An apparently increasing proportion of voters cannot be counted upon to have the political knowledge needed to act as competent citizens.

I go on to address the link between civic literacy and support for Trump and the Republicans in the US today, with its rigid two-party system. Using secondary data from a number of related studies, we find that, overall, support for Trump is not only negatively related to political knowledge, but also to other factors that make his supporters unaware of their being misinformed. This, I contend, is a new element, and linked especially to media use. The informational deficits, in turn, make Trump supporters especially susceptible to populist emotional appeals relying on "false news" that exploit their anxieties. What unites populists these days is that they identify with the interests of the native born, seeking to keep outsiders out of the country, mobilizing against "elites" who side with the outsiders against the "real" people of the country. While in most democratic countries populists have formed new parties, in the context of the rigid American two-party system, they have largely succeeded at taking over the Republican party, mobilizing a sufficient number of registered Republicans to deny renomination to insufficiently loyal legislators.

I have been working in the area of comparative political knowledge for at least two decades. Emerging from this literature is a consensus over the generally low level of political literacy or political competence in democratic 
countries. Overall, since it was seen as a manifestation of low political interest and attentiveness, low political knowledge has not been regarded as a threat to democracy. The bulk of respondents found in the research to lack basic political knowledge were understood to be politically passive, even when it came to voting. It was implicitly assumed that when circumstances warranted their participation, they would become more attentive and thus sufficiently informed. A corollary of this assumption was that they would seek the needed information through communications media that could be counted on to adequately provide the needed facts. The media could be counted on to provide sufficiently objective facts as long as the right to a free press and free expression were not threatened.

While it was acknowledged that there would be a group that rejected the premises of liberal democracy based on systematic misinformation, this phenomenon was not given attention in the literature on political knowledge since it was taken for granted that, except in periods of great instability like the 1930s, the workings of liberal democracy would keep such a group to a politically ineffective minority.

These assumptions made their way into our methodology. Representative samples of the population were to be given political knowledge tests, allowing us to compare different groups (by age, gender, region, educational attainment, as well as nationality, taking into account cultural differences). Specifically, it meant that wrong or "don't know" answers treated as were equivalent, since the former were basically a matter of a guesswork. In other words, to be uniformed or misinformed, in the end, amounted to the same thing.

The recent emergence of populist parties in democratic countries forces us to question these assumptions, something we are just beginning to do. As I have followed developments in Trump's America in particular, I am coming to the realization that we can no longer count on a large number of politically misinformed Americans to be open to becoming informed. The literature has not yet caught up with these developments, however. I could find only one research article investigating the distinction between uninformed and misinformed, and it uses European data. In it, according to van Kessel Sajuria, and van Hauwaert (2020):

Recent research suggests that populist party supporters are not necessarily unsophisticated protest voters. This leads us to question the still popular assumption that these individuals are politically uninformed. Simultaneously, given the current political and media climate and debates about 'fake news,' this article asks to what extent misinformation, i.e., the possession of erroneous political information, stimulates populist party support. Survey data from nine European democracies are used to assess to what extent populist party supporters differ from abstainers and non-populist party supporters in terms of their political information and misinformation. It is found...that political misinformation relates positively to support for right-wing populist parties. The findings provide a first empirical and comparative contribution to recent debates that seek to connect misinformation and political behaviour.

In the rest of this article I take an approach based on this distinction. A great deal has been written about modern liberal democracy, stressing majoritarian decision making, respect for the rights of minorities, and freedom of expression. Yet, in the context of what is happening today, one dimension is missing, namely the capacity to resolve disagreement through appeals to objective facts. Experts and commentators have taken for granted, as the well-known expression put it, "you can have your own opinion, but not your own facts." I return to this distinction and its relationship to populist attitudes after first outlining what we know of comparative political knowledge in democratic countries.

\section{The Political Knowledge of Americans in Comparative Perspective}

An early signal of acute differences 1 among developed democracies emerged from the International Adult Literacy Survey (IALS). This highly sophisticated cognitiveproficiency test, developed jointly by Statistics Canada and the OECD, sought to assess the extent to which people over 16 years of age in each country possess the kind of literacy needed to be effective citizens in today's world. The study tested the level of comprehension of three types of written materials: 1) prose literacy-the ability to understand and use information from texts such as editorials, news stories, poems, and fiction; 2) document literacy - the ability to locate and use information from documents such as job applications, payroll forms, transportation schedules, maps, tables, and graphs; and 3) quantitative literacy-the ability to perform arithmetic functions such as balancing a checkbook, calculating a tip, or completing an order form.

The specific literacy tasks designed for the IALS were scaled by difficulty, divided into five broad literacy levels. Level 1 indicates very low literacy skills, where the individual may, for example, have difficulty identifying the correct amount of medicine to give to a child based on the information printed on the package. Figure 1 displays the average percentage scores for each country in the three tests of those that scored in the lowest category, which may be described as the "level of functional illiteracy." As we can see, those that have the fewest falling in the functional illiteracy category turn out to be the Nordics followed by the Netherlands and Germany. Australia fits into a wide middle category along with Belgium, Switzerland, Canada, and New Zealand, with those at the bottom, the US, Britain, and Ireland, which have the greatest number falling in the functional illiteracy level. 


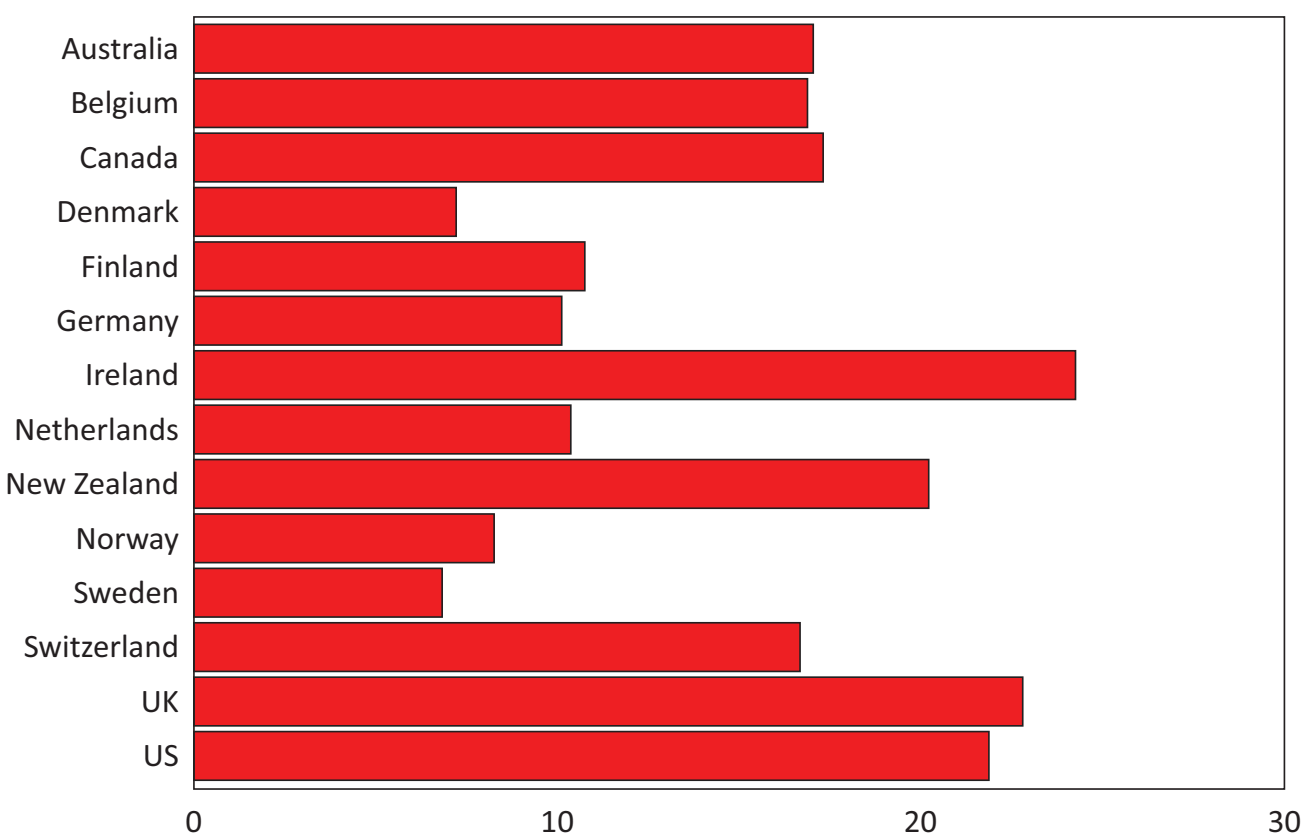

Figure 1. Functional illiteracy level (IALS category 1 average).

Given that in modern societies information about politics is in large part distributed in written form, we expect to find a relationship between functional illiteracy and political knowledge, and thus a low level of political knowledge in the US. There is no shortage of documentation attesting to this (see e.g., Annenberg Public Policy Center, 2014; Rauch \& Wittes, 2017). The best comparative political knowledge data is found in surveys conducted for the Comparative Study of Electoral Systems (CSES) based at the University of Michigan. In the first three rounds, participating countries included three political knowledge questions, designed to provide some overall comparability (the national research teams were instructed to formulate the three questions in such a manner as to have different levels of difficulty, with one question being answered correctly by $2 / 3$, another by $1 / 2$, and the last by $1 / 3$ of the respondents). It was only the fourth wave, however, comprising surveys using the fourth module, that included questions that were the same for all participating national surveys.

The data in Figure 2 is drawn from the combined results to the questions posed in the first three waves. Taken together, the responses in the 22 longstanding democracies in the CSES give us a total of 102,783 respondents. Figure 2 sets out the levels of political knowledge in CSES countries that reported results for at least two election surveys at least five years apart between 1996 and 2012. One conclusion emerging from the charts is of generational decline: In all but one (Germany 2002) of the 76 election surveys, young people were less politically knowledgeable than their elders. Moreover, in most countries the generational gap between young citizens and everyone else was growing over time, though punctuated by fluctuations due to the changing content, and thus difficulty of the questions. Figure 3 combines the data in Figure 2, setting out the average difference between the two age groups for all the surveys carried out in each period. As we can see, the CSES data fits neatly into 5-year intervals for the four waves. Because each period contains the results from many different countries, the effect of the fluctuations based on question difficulty is effectively canceled out. Thus, we see a steady increase in the generation gap, rising from about a quarter of a question to almost half.

Overall, for the decades leading up to about 2012, a clear relationship between declining political knowledge and the arrival of what is termed the Internet Generation (Milner, 2010) has been established. In order to compare countries' level of political knowledge per se, and not just generational differences, we need to use the more recent wave 4 data (up to and including 2016), when the same political knowledge questions (see Supplementary File, Appendix 2) were posed in each country. The questions in module 4 were based on recent facts, while those in the earlier modules were a mix of facts about institutions as well as recent and historical facts, which would explain the less apparent generational difference. Unfortunately, while the results found their way into several research studies, the more comprehensive research projects based on planned longitudinal use of the data had to be abandoned when the questions were not included in the subsequent CSES waves. Thus, there is no data for elections after that date. In the Supplementary File Appendix 1, the results are broken down by question. Overall, with the exception of the question on unemployment levels, a matter of acute concern to younger respondents, older respondents are still more informed than younger ones in most countries, though the picture is cloudier than in earlier years. 

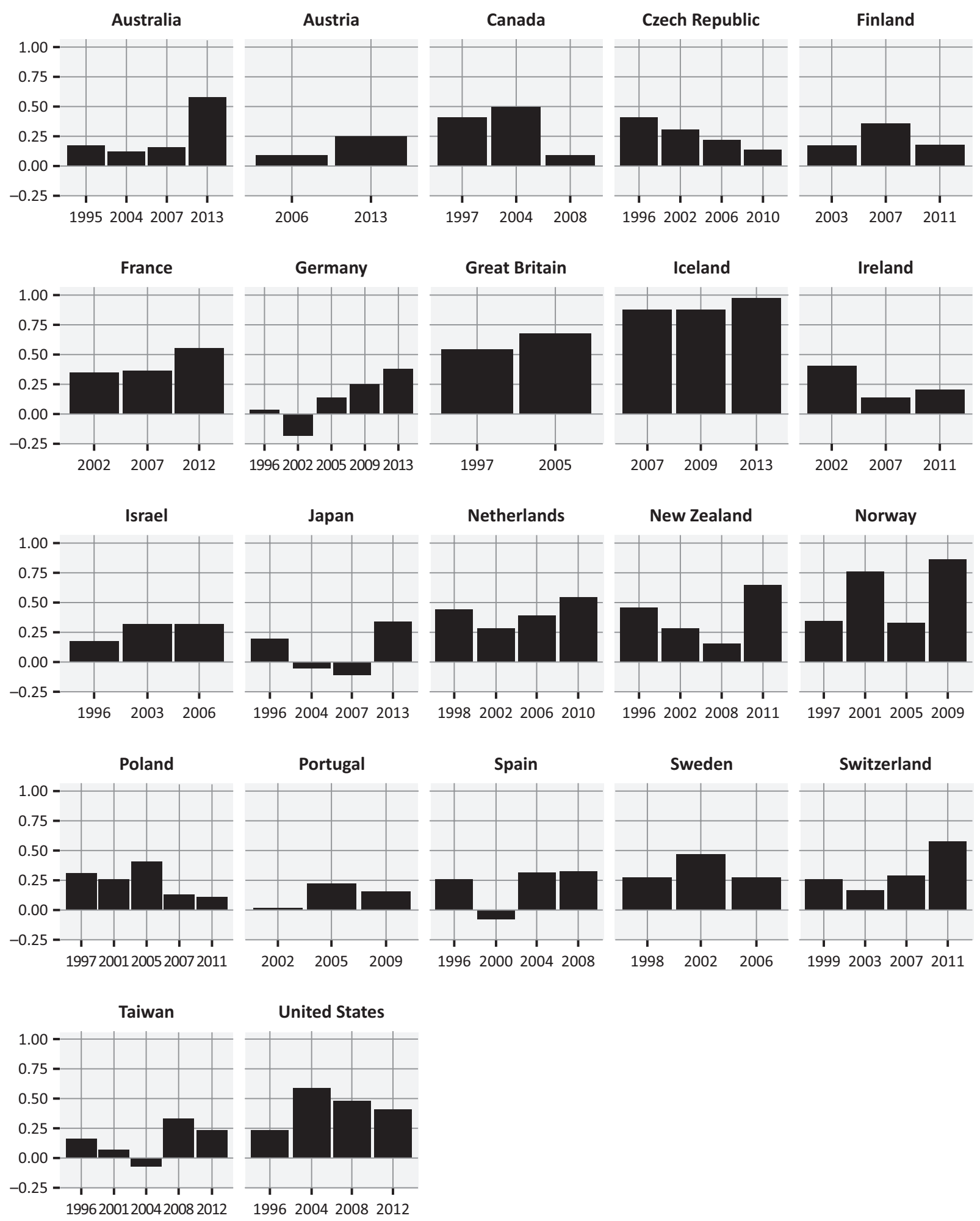

Figure 2. Difference in political knowledge: Between 18 to 25 -year-olds and 26 to 65 -year-olds.

The data represented in Figure 4 suggest that the key differences are now cross-national. This becomes clearer in Figure 5 where we combine the CSES data in Figure 4 into simple bar graphs setting out thus the average number of correct answers for all respondents at the times of elections in each country. We can see that, overall, the differences in literacy, which were identified in the IALS surveys and visualized in Figure 1, are reproduced to a certain degree here. Among developed countries, on average, the highest scores are those in Western Europe, next come the English-speaking countries (excluding the US), then those in Asia. They are followed by Eastern European countries and, finally, developing countries. The US is the clearest outlier with levels closer to the latter. 


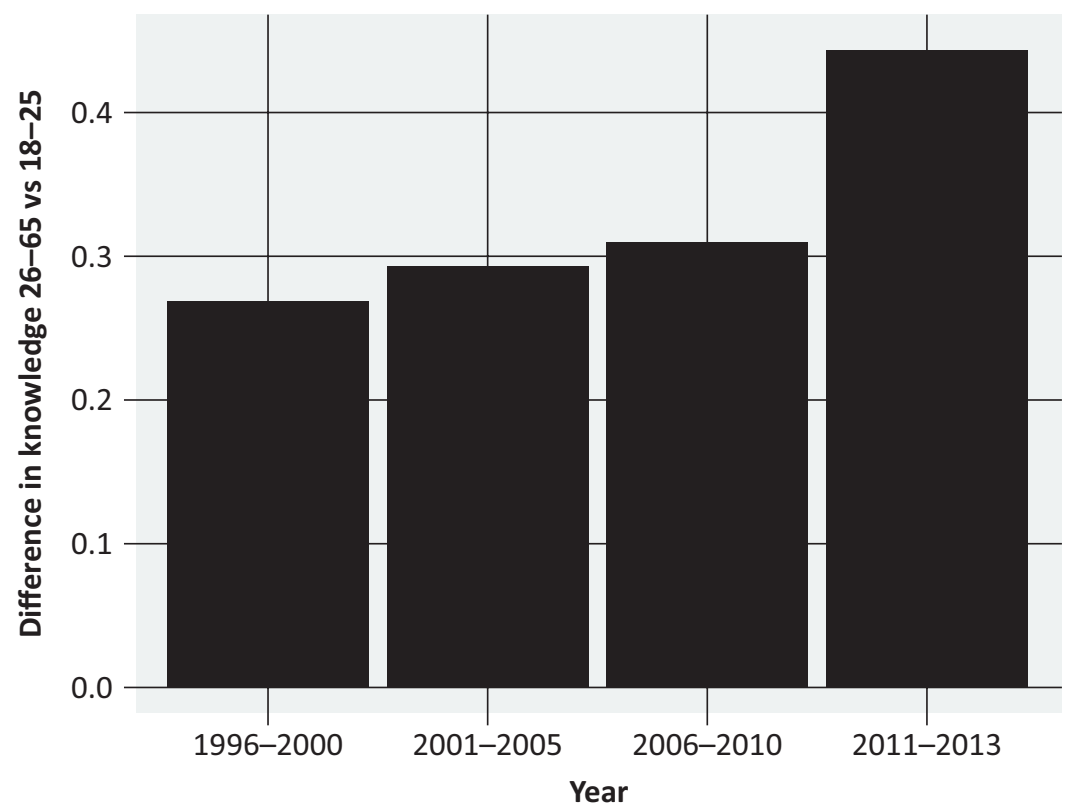

Figure 3. Average difference in political knowledge between 26-65 and 18-25-year-olds.

A glance at the charts suggests that it is the countries lower in civic literacy that, other things being equal, are more vulnerable to the emergence of populist parties. A clear exception is Greece, but other research suggests that civic literacy is high in Greece since citizens need to know something about politics in order to conduct ordinary business given the way the system operates. Of course, another factor linked to the emergence of populist parties and attitudes is geopolitical, in Greece and Austria in particular, in the form of an awareness of vulnerability to uncontrolled migration.

The data also reflects a relationship to which I have drawn attention in my comparative analysis, namely that between civic literacy and what I have termed the sustainable welfare state (see Milner, 2010). Recently, as Sitaraman (2019) argues, as inequality rises with the retreat from the welfare state in many countries, to still find meaning somewhere in their lives, people retreat to tribalism and identity groups, with civic associations replaced by religious, ethnic, or other cultural affiliations:

When taken to an extreme, social fracturing into identity groups can be used to divide people and prevent the creation of a shared civic identity. Selfgovernment requires uniting through our commonalities and aspiring to achieve a shared future. When individuals fall back onto clans, tribes, and us-versusthem identities, the political community gets fragmented. It becomes harder for people to see each other as part of that same shared future. Demagogues rely on this fracturing to inflame racial, nationalist, and religious antagonism, which only further fuels the divisions within society.

Here I look specifically at the micro-relationship between populism as currently finds expression in politics (i.e., support for Trump and the Republicans) in the low civicliteracy US. Would-be populist leaders undermine political institutions, questioning their legitimacy, for example in Donald Trump's false claims about widespread electoral fraud. Populist discourse rejects nuanced political arguments in favor of conspiracy-laden attacks that reject the political legitimacy of one's opponent. It tends to encourage politics based on fear and resentment rather than informed policy debate. Populist political actors often seek to mobilize exclusionary collective identities, appealing to ethno-nationalism. It is not a coherent worldview but a dynamic framing strategy, analytically separable from the political ideologies it expresses (see Bonikowski, 2017).

The Trump phenomenon fits this conception of populism, which is in fact not an "ism," like socialism or fascism, and fits nowhere on the standard left-right scale. That's because it has no underlying programmatic content, except, in the current context, keeping outsiders out of the country and replacing their elitist sponsors in politics and the media with true patriots. It is understandable why populism has increasingly come to resonate with voters who are experiencing frustrations associated with rapid social change.

\section{Populism and Political Knowledge in the US}

There is no shortage of interest in populist developments currently. Here is an excerpt from the call for papers to the September 2019 American Political Science Association meeting sent out early that year, a call which drew scores of papers, something inconceivable at similar meetings only a few years earlier:

No recent political development has been more striking than the rise to power of self-identified pop- 

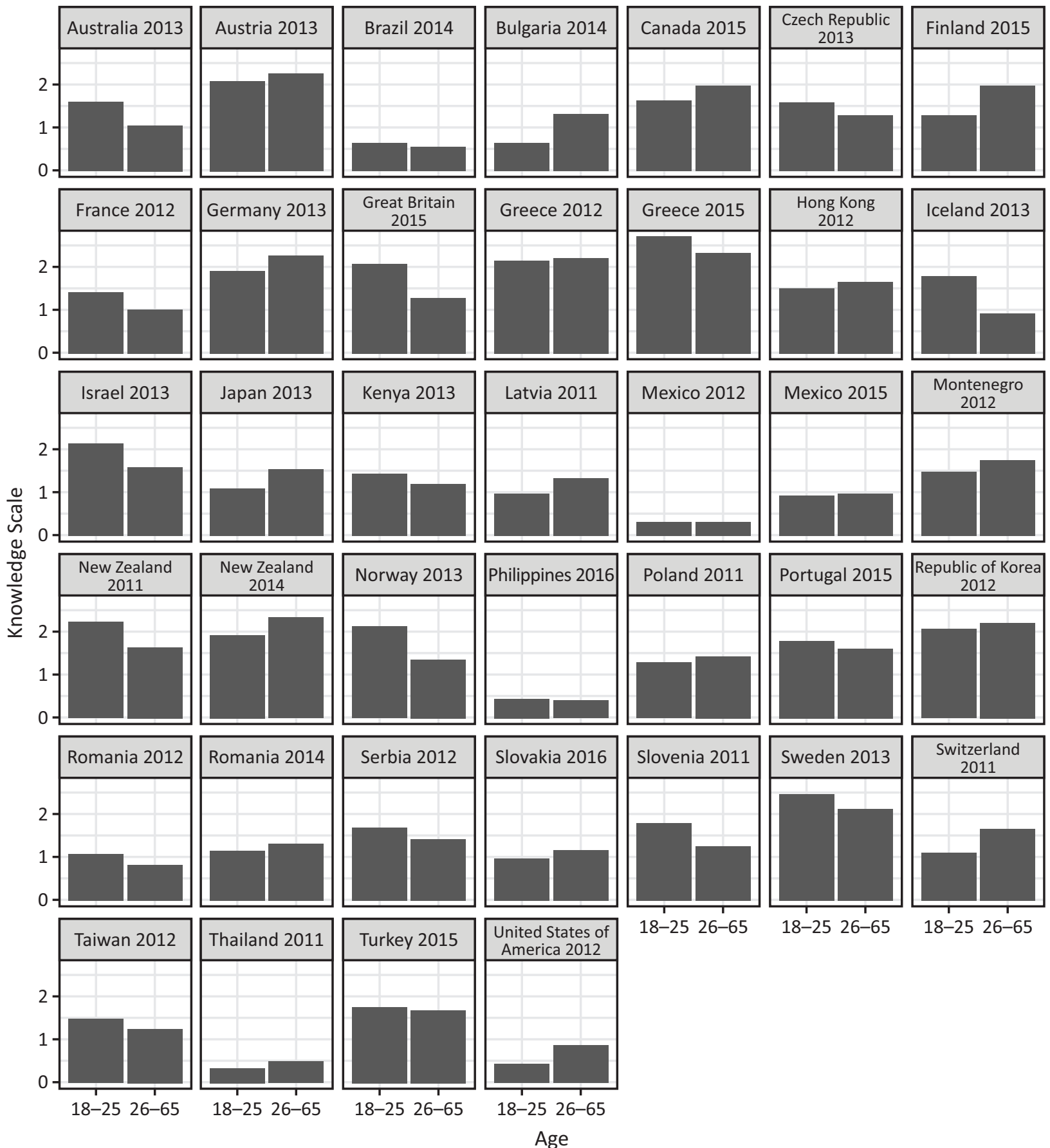

$18-2526-65$

$18-25 \quad 26-65$

$18-25 \quad 26-65$

Figure 4. Difference in political knowledge by country from CSES Wave 4.

ulist movements around the globe, whose main unifying trait is their claim to champion "the people" against entrenched selfish "elites." These movements display differences that have sparked debates over which, if any, should be called "populist"; how they compare with past "populisms"; and what "populism" is. The current partisans, often labeled populist, have more often been on the right than the left, including anti-immigrant, anti-globalization, ardently nationalist parties such as Fidesz in Hungary; the Law and Justice Party in Poland; and the Trump
Republicans in the United States. (American Political Science Association, 2018)

To better understand this phenomenon, we can start from a feeling of dissatisfaction with life generally, which has been found to translate into the above identified attitudes. In the case of Brexit, Alabrese, Becker, Fetzer, and Novy (2018) using a sample of around 13,000 respondents found a strongly significant association between life satisfaction and support for leave, those who were dissatisfied with life overall were around $2.5 \%$ more likely 

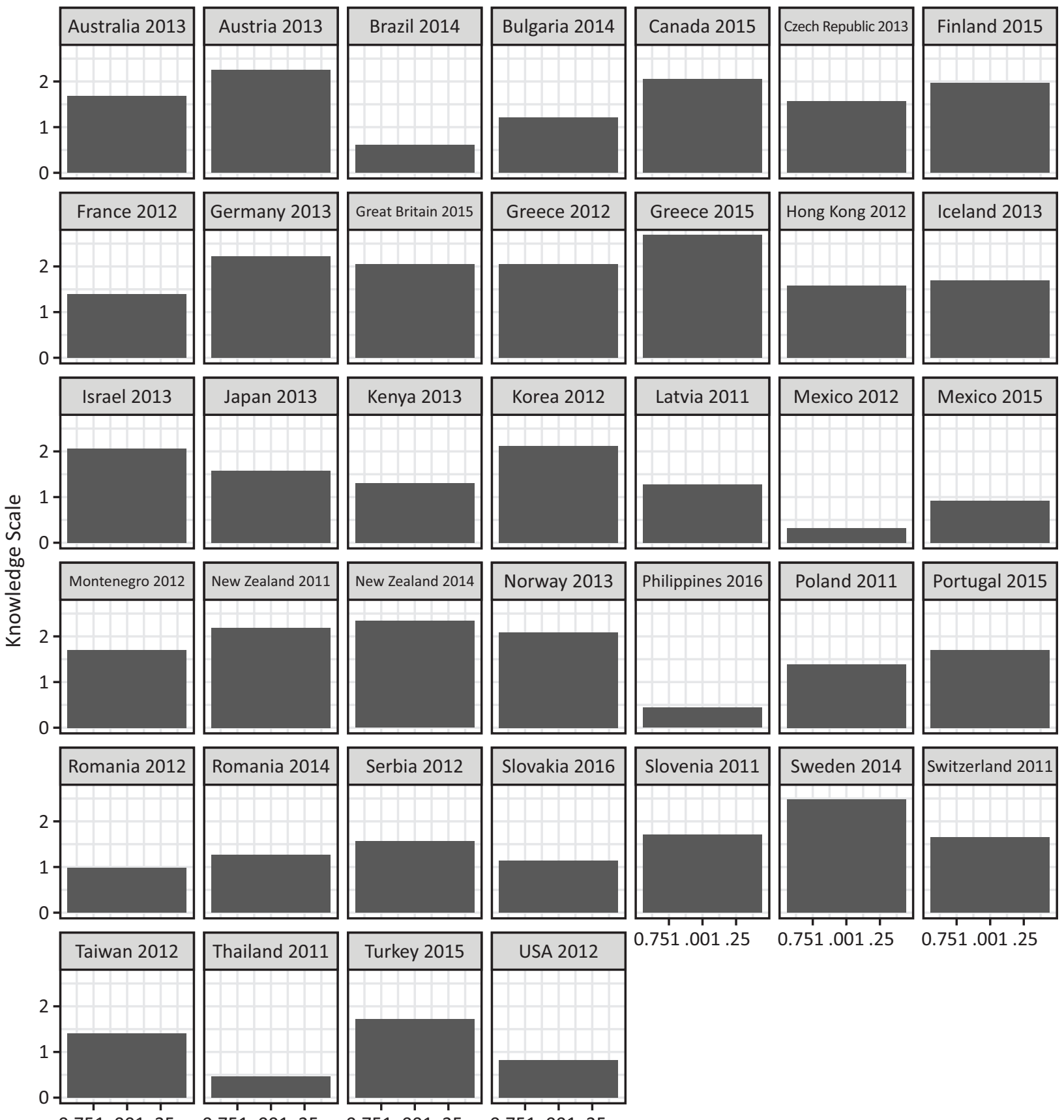

0.751 .001 .25

0.751 .001 .25

0.751 .001 .25

0.751 .001 .25

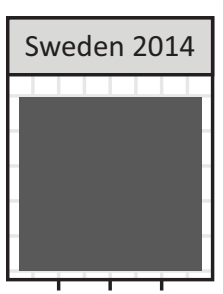

0.751 .001 .25

0.751 .001 .25

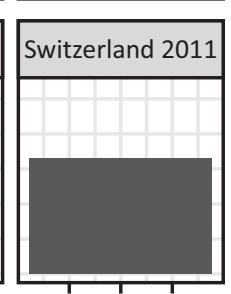

0.751 .001 .25

Figure 5. Average of correct answers in CSES Wave 4.

to answer yes to the question of whether the United Kingdom should leave the European Union. This is true both at the individual-level and at the aggregate localauthority level, where the percentage of people dissatisfied predicts the leave vote.

Turning the US, using data from Gallup surveys of US residents on various aspects of their subjective wellbeing, Herrin et al. (2018) find a correlation between subjective well-being and Trump voting. Placing counties into 6 categories based on the percentage point electoral shift from 2012 to 2016, they find that the percentage of people placing themselves near the bottom in subjective well-being, both currently and in five years' time, is significantly associated with larger swings towards the Republican Party. In counties where the Romney to Trump swing was smaller than $-10 \%$, only $3.4 \%$ of people were of low life satisfaction (0-4 on the 0-10 scale). But in strong Trump voting areas (where the swing was greater than $10 \%$ ) this more than doubles to $7.1 \%$.

Life satisfaction, we know, correlates with political participation, both of which are positively linked to education. According to Flavin and Keane (2011), those more satisfied with life are likely to vote and participate in the political process at a magnitude that rivals the effect of education. Nate Silver, in his " 538 " assessment on of the 2016 election result, pointed out that Hilary Clinton won 
the 50 best educated US counties, and Trump the 50 least educated (Silver, 2017). In the context, thus, of a negative relationship between populism and both life satisfaction and education, it is reasonable to expect to find that populist attitudes correlate with low political knowledge (see also Stanley, 2008).

In part, the informational deficits that make these voters especially susceptible to emotional populist appeals simply reflect the quality of information they receive which exploit these anxieties. Trump supporters, we know, more frequently rely on information media that are most likely to provide false information that confirms their biases. In an analysis of millions of American news stories Benkler, Faris, and Roberts (2018) conclude that, unlike most news outlets that seek to adhere to facts and run corrections of false reports, conservative media are more concerned with confirming their audience's biases, fearing angry reactions to exposures of falsehoods from core viewers. As Jane Mayer (2019) noted, on Fox News when falsehoods are exposed, core viewers often react angrily, noting that after Shepard Smith, the Fox News anchor, contradicted Trump's scaremongering about immigrants viewers lashed out at him on social media.

While we have no systematic data linking Trump support with political ignorance, there is no shortage of suggestive partial data. For example, according to Kurt Andersen (2017), when asked: "Do you believe that a secretive power elite with a globalist agenda is conspiring to eventually rule the world through an authoritarian world government?" $34 \%$ of Republican voters said yes.

Poundstone (2016) reported on the results of several quizzes. He first asked a sample of 404 adults whether dinosaurs lived at the same time as humans. $25 \%$ of Trump supporters agreed, but only $8 \%$ of those who had voted for Clinton. Then he asked them three questions getting at basic political knowledge: to identify Vladimir Putin, the majority party in Congress, and the official who nominates Supreme Court justices. Those who disapproved of Trump averaged 2.45 correct answers (out of three), while his supporters averaged 2.21. The scores for Clinton, 2.28 and 2.55, were reversed. He cites a survey showing much greater support for a US-Mexico border wall by those with low scores on a set of 16 general knowledge questions, including locating North Carolina on a US map and knowing which came first, Judaism or Christianity (Poundstone, 2016).

Related to this is an important contribution to this discussion in a recent publication by Fording and Schram (2017, p. 670) based on data from the American National Election Studies 2016 pilot study which surveyed a nationally representative sample of 1200 adults. The authors conclude that the Trump campaign exploited a void of facts and reasoning among:

Low information voters...that made them more vulnerable to relying on emotions about Mexican immigrants, Muslim refugees, and African American cit- izens, as well as their disdain for the first African American President, Barack Obama. As a result, these Trump supporters were less in a position to want or be able to question Trump's...campaign of misstatements, untruths, and lies. (Fording \& Schram, 2017)

Two measures were combined to gage political knowledge, one indirectly through "need for Cognition" (NFC), the other directly of political knowledge. Those with low NFC rely more on cognitive short cuts such as the statements of celebrities on issues. Two questions, the scores on which were combined, got at this dimension: "Thinking is not my idea of fun"; and "I would rather do something that requires little thought than something that would challenge my thinking ability." Of the sample, $50 \%$ were found to be low in NFC, $15 \%$ high. The latter measure consisted of two questions: 1) How many years is a senator's term?; and 2) on which of these does the government spend least-Foreign aid, Medicare, National Defense, and Social Security? $46 \%$ got neither question right; $33 \%$ got one right, and $22 \%$ got both right. The two indicators correlated quite strongly: Only $7 \%$ of those getting both right were also ranked as low in NFC.

Controlling for level of education, party identification, (on a seven-point scale from strong Democrat to strong Republican), ideology (on a seven-point scale from extremely liberal to extremely conservative,) family income, gender and age, and limiting the sample to whites, the authors tested the relationship of both measures to feelings about Clinton and Trump. The result of subtracting the score for Clinton from that for Trump (the thermometer gap) correlated strongly with political knowledge and NFC. Preference for Trump among those low in political knowledge was $20 \%$ higher and for those low in NFC it was $12 \%$. Nothing similar had been found regarding Mitt Romney and other recent Republican candidates.

Breaking down the results, the authors found that almost $80 \%$ of the effect of political knowledge flowed through six items, each significantly related to support for Trump over Clinton: 1) belief that Obama is a Muslim; 2) belief that whites are losing jobs to minorities; 3 ) belief that Muslims are violent; 4) support for immigration restrictions; 5) racial resentment against blacks; and 6) belief that the economy has worsened over the last year. Belief in the false assertion that Obama is a Muslim had the strongest relationship-three times that of the worsening economy, and twice the effect of the other four questions.

This is part of the explanation. But there appears to be, I argue, a more profound development that was less present before the age of Trump, something our standard analyses of the effects and causes of political knowledge have not incorporated. Before Trump, low civic literacy in the US had no partisan hue. Now things have changed. Anson (2018) surveyed 2,606 American adults online as to their political knowledge. He found that those who performed worse were more likely to overestimate their performance. Moreover: 
When I asked partisans to "grade" political knowledge quizzes filled out by fictional members of the other party, low-skilled respondents gave out scores that reflected party biases much more than actual knowledge.....More often than not, this means that partisans will think of themselves as far more politically knowledgeable than an out-partisan, even when that person is extremely politically knowledgeable. (Anson, 2018, p. 1173)

This was more the case among Republicans than Democrats, the former using partisan cues to judge peers' political knowledge to a greater extent confirming, Anson noted, the findings of an emerging literature on "asymmetric polarization" (Anson, 2018). To put it simply, the bulk of those identifying themselves as partisan Republicans, which by 2020 are effectively almost all supporters of Trump, are not only unaware of their being politically misinformed, but dismiss efforts to bring out the actual facts as politically motivated. Understandably, thus, when the facts do come out, the effect, as the polls continue to show, is negligible.

Barber and Pope (2019) carried out online surveys of almost 1600 respondents who completed a political knowledge quiz, which asked five questions: the number of years served by a Senator, as well as the name of the current Secretary of Energy, from four possibilities; which party is more conservative on the issue of healthcare; which currently controls the House of Representatives; and on which of four different programs the Federal government spends the least? They found evidence that Republicans use partisan cues to judge peers' political knowledge to a greater extent than do Democrats, coinciding with the actual polarization in the American electorate:

We find that low-knowledge respondents, strong Republicans, Trump-approving respondents, and selfdescribed conservatives are the most likely to behave like party loyalists by accepting the Trump cue-in either a liberal or conservative direction. These results suggest that there are a large number of party loyalists in the United States [whose]...claims to being a self-defined conservative are suspect, and that group loyalty is the stronger motivator of opinion than are any ideological principles. (Barber \& Pope, 2019)

Indeed, there is an emerging literature that begins to assess these phenomena, using concepts like cult (Heffernan, 2020), as well as tribalism (see Rauch \& Wittes, 2017).

\section{Institutional Arrangements and a Media Environment Favouring Trumpian Populism}

The negative portrayal of Trump in the mainstream media though accurate, has, if anything, bolstered Trump supporters in their views: The more strongly his statements-however distant from the facts-stick it to the elitist liberals, i.e., the "Democrats," the more fervent, apparently, is their support. In this war, on the other side are the "lamestream" news organizations, the "enemies of the people" (an expression notably first used by Vladimir Lenin after coming to power in the decree of 28 November 1917 declaring the opposing Constitutional Democratic Party to be filled with enemies of the people who are to be arrested immediately). Politically, thus, the priority for Trump is to mobilize his hard-core base, which, at this writing, remains large enough to keep almost all Republican legislators from straying, fearing defeat in the primaries more that in the general election, and verbal if not physical violence.

In this context, as noted at the outset, Trump supporters are not uninformed but misinformed. While factual information can have an effect on the views of the former, this is not the case with the latter. Trump supporters who are ignorant by the standards of our political knowledge tests do not see themselves that way. Hence his approval rate is unaffected by the revelation that, as of this writing, he has uttered 16,500 false or misleading statements since taking office, according to the factcheckers. To take one example, the following was reported in The Washington Post:

President Trump held his longest campaign rally to date on Dec. 18, just as the House was voting to impeach him. We measured how much of what Trump said was accurate and how much was false. That meant going through Trump's often-dizzying remarks line-by-line, nearly 12,000 words in total.... Of the 179 statements we identified, 67 percent were false, mostly false or devoid of evidence. That's 120 factfree claims.

At the December rally in Michigan, Trump falsely claimed he won the state's "man of the year" award. He falsely claimed to have set military spending records. He claimed-again, falsely-that $401(\mathrm{k})$ retirement accounts have gained up to 90 percent in value during his presidency. He falsely claimed Michigan had more auto industry jobs. He inflated the attendance at his rally and made up stories about several Democratic rivals. He took credit for major legislation and economic growth trends and NATO spending that came well before he took office. ("Anatomy of a Trump rally," 2020)

It is in the context of intense as well as asymmetric polarization that this distinction has become significant. As Rauch (2019) argues, "emotional identification with a partisan team is driving ideology, more than the other way around," that, in the US today, "party equals tribe." He cites Pew Research Center (2018) data showing that more than three-quarters of respondents in both parties concur that Republican and Democratic voters can't even agree on basic facts, and that, compared to 1994, the 
share of Republicans with very unfavorable opinions of the Democratic Party went from $17 \%$ to $43 \%$ in 2014 , while the share of Democrats with very negative opinions of the Republican Party went from $16 \%$ to $38 \%$. Among them, the vast majority say the opposing party's policies represent a threat to the nation's well-being:

What we fear, we tend also to hate....Partisans are not so much rallying for a cause or party they believe in as banding together to fight a collective enemypsychologically and politically a very different kind of proposition.... Fans of opposing sports teams perceive different events in close calls. Fans of opposing political parties perceive different facts and take different policy views depending on which party lines up on which side. Presenting people with facts that challenge an identity-or group-defining opinion does not work; instead of changing their minds, they will often reject the facts and double down on their false beliefs.

Although the result was to reverse Republican orthodoxy on everything from entitlement spending and trade protectionism to global alliances and the $\mathrm{FBI}$, partisans felt no psychological inconsistency or lurch, because, as a result of their ideological somersaults, they continued to be aligned with the same in-group and opposed to the same out-group. (Rauch, 2019)

Older, white, less educated males in blue states overwhelmingly fit the above characterization. Not only does their social milieu reinforce these sentiments, but so do the social and electronic media from where they get information. They have Fox News and other pro-Trump electronic media sources like Breitbart, and national and local phone-in hosts in stations owned by Sinclair, Trinity broadcasting network, and Nexstar. According to Woolley and Joseff (2020):

Emerging technologies, including synthetic media, virtual and augmented reality, and biometric-powered mass surveillance have the potential to worsen the disinformation crisis in a number of ways. However, it is not only the sophistication of these technologies that poses the greatest challenge, but the interaction with the demand-side drivers.....News consumers who are heavily invested in false political narratives are often quite knowledgeable about (and skeptical toward) independent media.

With the latest communications technology, recognition of a voice or picture is no assurance of authenticity. With the development of synthetic media and "deepfakes," every digital communication channel, audio, video, or even text, can be imperceptibly subverted. To illustrate this, we can cite as just one example of what is apparently happening regularly the following from a report in The New York Times about a "video of Democratic presidential candidate Joe Biden that was selectively edited to falsely suggest he made racist remarks during a recent speech made the rounds Thursday on social media, raking in more than a million views on one tweet alone" (Corasaniti, 2020). Also:

In the edited clip, which was less than 20 seconds long, Biden says, "Our culture is not imported from some African nation or some Asian nation." Social media users paired the video with comments like "It's almost like Joe Biden is a racist....The clip was taken from $A B C$ News coverage of Biden speaking for more than an hour in Derry, New Hampshire, on Dec. 30, 2019. A review of the full video shows that Biden was commenting on changing the culture around violence against women. In discussing the difficulty victims face reporting sexual assault on college campuses, he said, "Folks, this is about changing the culture, our culture, our culture, it's not imported from some African nation or some Asian nation. It is our English jurisprudential culture, our European culture that says it is all right."...The video spread rapidly on social media, amplified by many right-wing verified users on Twitter, including reporters at conservative news outlets, the former speaker of the Missouri House and Republican strategists, according to data compiled by Vinesight, a company that detects disinformation on social media. (Corasaniti, 2020)

Finally, American institutional arrangements exacerbate this situation, enshrining the two-party system, giving extra political weight to the blue regions far from the metropolitan centers and most prone to the false news syndrome. We turn to this aspect next before addressing what, if anything could be done to meet the challenge.

\section{Institutions, Policies, and Political Knowledge}

\subsection{Civic and Adult Education and the Media}

The challenge is significant. It is not a matter of convincing Trump supporters that his policies conflict with theirs, since his defying Republican orthodoxy on everything from entitlement spending and protectionism to global alliances and the FBI caused no discomfort for his partisans. Clearly adult education, via the media or otherwise, is a dead end. This need not be the case as far as youth focused civic education is concerned, since it is offered an age where its recipients are not likely to have yet come to accept misinformation as knowledge. But, in the context of emerging communications technology, what we know so far is not reassuring.

With regard to young people, we would expect that a key component of political knowledge is the quality and availability of civic education. I tested the effects of civic education in a survey in 2006 with the Center for Information and Research on Civic Learning and Engagement (CIRCLE), at the University of Maryland. Its Civic and Political Health Survey updated a previ- 
ous youth survey (Keeter, Zukin, Andolina, \& Jenkins, 2002), telephone interviews were conducted with a nationally representative sample of 1,765 Americans, of which 1,209 were aged 15 to 25 posing three political knowledge questions. For this second round, five questions were added, so that the resulting questionnaires allowed for 8 possible correct answers (the list of questions can be found in Appendix 3 of the Supplementary File).

Political knowledge was found to be low, especially among young people. Out of a possible score of 7 , the mean of correct answers was 2.12 for young Americans as compared to 2.89 for those 26 -plus. The results of the responses to the specific questions were the most glaring, with $55 \%$ of young Americans unable to name one permanent member of the UN Security Council (i.e., including the US), and $56 \%$ unable to identify citizens as the category of people having the right to vote.

The CIRCLE survey then asked the student respondents whether their classes required them to keep up with politics or government, either by reading a newspaper, watching TV, or going onto the Internet. The effect of such a reported requirement did not quite attain significance, but the reported frequency that history, government, or social studies teachers encouraged students to discuss political and social issues over which people have different opinions did significantly correlate with political knowledge (see Milner, 2007).

In observing civic education programs in a number of countries (see Milner, 2010), I have noted the importance of designing and targeting civic education programs to bring political knowledge to individuals low in the requisite home and community resources, supplemented by government-supported programs affecting the supply of political knowledge in such areas as political party financing, information dissemination, voter registration, and mock parliaments. Moreover, since these young people are frequently potential dropouts, civic education is most effective when offered at a time when they are still in school but close to voting age, and in a form most likely to appeal to them. Our knowledge in this area is, however, limited by the absence of even minimal systematic comparative data on basic aspects of civic education such as the hours of teaching time involved and whether it is compulsory and required for graduation. What we do know is primarily based on American studies, which suggest that civic education in the US is markedly skewed toward constitutional history and voluntary community participation, avoiding addressing partisan issues and, thus, political misinformation (see Milner, 2010). It is hard to imagine, in the context of populist and anti-populist polarization, how educational authorities could do otherwise.

This, it would seem, is insufficient to prepare young Americans for the systematic misinformation around them. Lowering the voting age to 16 , as proposed by Franklin (2004), who argues that because the period in a young person's life after leaving the parental home typically at age 18-20 is unsettled, and thus a bad time to develop habits related to voting. However, in the context of an information world comprised of Internet-based subcultures consisting of chat rooms, blogs and the like, one wonders if one can really count upon adolescents getting information from family discussions of the news over supper.

Lowering the voting age, combined with increasing the years of compulsory education could place young potential voters in a position to benefit by combining civics classes with complementary activities, such as the mock elections that are carried out in many countries among high school students, by organizations like Kids Voting USA, which arranges for teachers in most states to help students gather information about candidates and issues, so that, on election day, they cast their ballots in special booths. Whether such simulations, like the Minitinget in Norway (see Milner, 2010) would they have an effect in the US today is an open question. According to the National Center for Science education (https://ncse.ngo/research), more than half of American students are inaccurately taught about evolution and climate change.

\subsection{Electoral Arrangements}

An article by Grönlund and Milner (2006) placed countries' electoral institutions on a continuum based on how close to proportionality was the number of seats won by each party compared to the votes it received. The method used was to quantify the dispersion of political knowledge among educational attainment categories by calculating the variation from the mean for each CSES country of the average political knowledge score in the group with the lowest level of education. We found that overall, as party outcomes become more proportional to popular support, political knowledge becomes less dispersed, less dependent on formal education.

Clues of a relationship between the electoral system and the knowledge required to cast a meaningful can be found in the literature focusing on the ideological reputation, ideological coherence and historical consistency of parties (Merolla, Stephenson, \& Zechmeister, 2014). Brader and Tucker (2012) found that party labels are more effective in older, more stable systems, and Lau, Patel, Fahmy, and Kaufman (2014) found that "ideological distinctiveness" of the parties increases citizens' ability to cast a correct vote. Turning to the US, we know that a "positive" effect of the extreme polarization has led to far greater "correct" votes (i.e., conservatives supporting Republicans and liberals voting Democratic). Given the institutional arrangements, a rigid two-party system, primaries, and the extra weight of smaller rural (typically older and white) states in the electoral college, and the ability of states to set their own rules of eligibility, the Trump supporters are assured of continuing to dominate one of the two parties even after he is gone from the scene.

There is little indication that this could change in any fundamental way. Third parties have neither the re- 
sources nor incentive to mount a campaign to get on the ballot state by state. The Supreme Court has refused to step in in cases partisan redistricting, and changes affecting the electoral college would require a constitutional amendment, since there is no reason to believe that the efforts in a handful of states to allocate electoral college votes proportionally rather than winner-takes-all will catch on.

\section{Conclusion}

Given the underlying wider societal developments taking place, we should not harbor any illusions. The growing polarization in certain modern societies, including, and especially, the US, between the growing metropolitan regions and those left behind in smaller towns and rural areas is compounded by the digital revolution that creates separate echo chambers through which relevant information-and misinformation-is filtered. And we know, for example, how this was used in highly sophisticated targeted data by Cambridge Analytica and Russia, which probably changed the outcome of the 2016 election, and possibly the Brexit vote.

The challenge could not be greater. But so are the stakes. In closing, the reader is referred to an important new work by Acemoglu and Robinson (2019) which draws the fine line between despotism and anarchy and tells the story of how infrequently societies were able to walk it for any lengthy period of time and how important trust in the institutions now under attack from the populists for maintaining prosperous, stable, well-governed, law-abiding, democratic, and free societies.

A lot will depend on the emerging generations. One thing we do know is that we need better and more comprehensive comparative data related to the level of and relationship between political misinformation and populist attitudes especially among members of this generation before we can hope to effectively address the challenge.

\section{Conflict of Interests}

The author declares no conflict of interests.

\section{Supplementary Material}

Supplementary material for this article is available online in the format provided by the authors (unedited).

\section{References}

Acemoglu, D., \& Robinson, J. A. (2019). The narrow corridor: States, societies, and the fate of liberty. New York, NY: Random House.

Alabrese, E., Becker, S., Fetzer, T., \& Novy, D. (2018). Who voted for Brexit? Individual and regional data combined (CESifo Working Paper, No. 7193). Munich: Center for Economic Studies and Ifo Institute.
American Political Science Association. (2018). APSA CGOTS 2019 call for papers. American Political Science Association. Retrieved from https://www. apsacgots.org/announcements/apsa-cgots-2019call-for-papers\#

Anatomy of a Trump rally: 67 percent of claims are false or misleading. (2020, January 7). The Washington Post. Retrieved from https://www.washingtonpost. com

Andersen, K. (2017, September). How America lost its mind. The Atlantic. Retrieved from https://www. theatlantic.com/magazine/archive/2017/09/howamerica-lost-its-mind/534231

Annenberg Public Policy Center. (2014, September 14). Americans know surprisingly little about their government, survey finds. Annenberg Public Policy Center. Retrieved from https://www.annenbergpublic policycenter.org/americans-know-surprisingly-littleabout-their-government-survey-finds

Anson, I. G. (2018). Partisanship, political knowledge, and the Dunning-Kruger Effect. Political Psychology, 39(5), 1173-1192.

Barber, M., \& Pope, J. (2019). Does party trump ideology? Disentangling party and ideology in America? American Political Science Review, 113(1), 38-54.

Benkler, Y., Faris, R., \& Roberts, H. (2018). Propaganda, manipulation, disinformation, and radicalization in American politics. New York, NY: Oxford.

Bonikowski, B. (2017). Three lessons of contemporary populism in Europe and the United States. Brown Journal of World Affairs, 23(1), 9-24.

Brader, T., \& Tucker, J. A. (2012). Following the party's lead: Party cues, policy opinion, and the power of partisanship in three multiparty systems. Comparative Politics, 44(4), 403-420.

Corasaniti, N. (2020, January 5). How a misleading Biden video spread. New York Times. Retrieved from https://www.nytimes.com/2020/01/07/us/politics/ biden-video-disinformation-spread.html

Flavin, P., \& Keane, M. J. (2011). Life satisfaction and political participation: Evidence from the United States. Journal of Happiness Studies, 13(1), 63-78.

Fording, R. C., \& Schram, S. F. (2017). The cognitive and emotional sources of Trump support: The case of low-information voters. New Political Science, 39(4), 670-686.

Franklin, M. N. (2004). Voter turnout and the dynamics of electoral competition in established democracies since 1945. Cambridge: Cambridge University Press.

Grönlund, K., \& Milner, H. (2006). The determinants of political knowledge in comparative perspective. Scandinavian Political Studies, 29(4), 386-406.

Heffernan, V. (2020, January 10). Call Trumpism what it is: A cult. Los Angeles Times. Retrieved from https://www.latimes.com/opinion/story/2020-0110/donald-trump-cult-steven-hassan-moonie

Herrin, J., Witters, D., Roy, B., Riley, C., Liu, D., \& Krumholz, H. M. (2018). Population well-being and 
electoral shifts. PLoS One, 13(3). https://doi.org/ 10.1371/journal.pone.0193401

Keeter, S., Zukin, C., Andolina, M., \& Jenkins, K. (2002). The civic and political health of the nation: A generational portrait. College Park, MD: CIRCLE.

Lau, R., Patel, P., Fahmy, D., \& Kaufman, R. (2014). Correct voting across thirty-three democracies: A preliminary analysis. British Journal of Political Science, 44(2), 239-259.

Mayer, J. (2019, March 4). The making of the Fox News White House. Fox News has always been partisan. But has it become propaganda? New Yorker. Retrieved from https://www.newyorker.com/magazine/2019/ 03/11/the-making-of-the-fox-news-white-house

Merolla, J., Stephenson, L. B., \& Zechmeister, E. J. (2014). Deciding correctly: Variance in the effective use of party cues. Paper presented at the Voting Experiment Workshop, Montreal, Canada.

Milner, H. (2007). The political knowledge and political participation of young Canadians and Americans. Paper presented at the Annual Meeting of the Canadian Political Science Association, Saskatoon.

Milner, H. (2010). The Internet generation: Engaged citizens or political dropouts. Hanover, NH: University Press of New England.

Pew Research Center. (2018, April 26). The public, the political system and American democracy. Political engagement, knowledge and the midterms. Pew Research Center. Retrieved from https://www.peoplepress.org/2018/04/26/the-public-the-political- system-and-american-democracy

Poundstone, W. (2016). Head in the cloud: Why knowing things still matters when facts are so easy to look up. New York, NY: Little, Brown.

Rauch, J. (2019). Rethinking polarization. National Affairs. Retrieved from https://www.nationalaffairs. com/publications/detail/rethinking-polarization

Rauch, J., \& Wittes, B. (2017). More professionalism, less populism: How voting makes us stupid, and what to do about it. Washington, DC: Brookings.

Silver, N. (2017, January 19). The real story of 2016. FiveThirtyEight. Retrieved from https://fivethirty eight.com/features/the-real-story-of-2016

Sitaraman, G. (2019, December 23). The collapse of Neoliberalism. New Republic. Retrieved from https://newrepublic.com/article/155970/collapseneoliberalism

Stanley, B. (2008). The thin ideology of populism. Journal of Political Ideologies, 13(1), 95-110.

van Kessel, S., Sajuria, J., \& van Hauwaert, S. M. (2020). Informed, uninformed or misinformed? A crossnational analysis of populist party supporters across European democracies. West European Politics. https://doi.org/10.1080/01402382.2019.1700448

Woolley, S., \& Joseff, K. (2020). Demand for deceit: How the way we think drives disinformation (Working Paper). Washington, DC: National Endowment for Democracy's International Forum for Democratic Studies.

\section{About the Author}

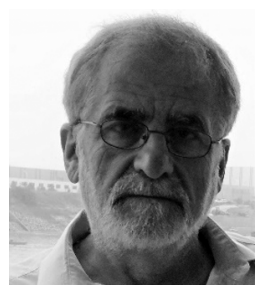

Henry Milner (PhD, Carleton) is an Associate at the Canada Research Chair in Electoral Studies in the Political Science Department at the University of Montreal. Between 2000 and 2012 he was Visiting Professor at the University of Umeå in Sweden. In 2004-2005, he headed the Chair in Canadian Studies at the Sorbonne. He has also been a professor or visiting scholar at various universities in Canada, Finland, Norway, Australia, and New Zealand. He has published 11 books including Civic Literacy: How Informed Citizens make Democracy Work, as well as books on Scandinavian politics and electoral reform. He is Co-Publisher of Inroads, the Canadian journal of public opinion and public policy. 